\title{
Field and laboratory studies of the water chemistry evolution of flowback fluids from a shallow shale gas well
}

TIANMING HUANG ${ }^{1,2}$, ZHENBIN LI $^{1}$, BERNHARD MAYER ${ }^{2}$, Michael Nightingale ${ }^{2}$, Zhonghe PANG ${ }^{1}$, XiAo Li $^{1}$, GUANFANG LI ${ }^{1}$

${ }^{1}$ Institute of Geology and Geophysics, Chinese Academy of Sciences, Beijing 100029, China. tmhuang@mail.iggcas.ac.cn (T.H.)

${ }^{2}$ Department of Geoscience, University of Calgary, Calgary, Alberta T2N 1N4, Canada. bmayer@ucalgary.ca (B.M.)

Environmental issues such as groundwater contamination, water shortage, and induced earthquakes induced by hydraulic fracturing or injection of wastewater have been paid attention to due to the rapid development of shale gas in China. The sources of pollutants potentially impacting groundwater quality can be directly from fracturing fluids, formation water, and solutes liberated by geochemical reactions between fracturing fluids, formation water, and shale.

To facilitate the study of geochemical processes during hydraulic fracturing and flowback, a scientific shallow shale gas well (depth $750 \mathrm{~m}$ ) was drilled into the Lower Silurian Longmaxi marine $\left(\mathrm{S}_{1} \mathrm{l}\right)$ formation, Guizhou, SW China, and only fresh water was used to fracture shale without adding any additives.

Preliminary results show that the conservative ions $\mathrm{Cl}$ and $\mathrm{Br}$ reveal the mixing relationship between the fresh water and formation fluids in the flowback water. Beyond mixing processes, $\mathrm{BaSO}_{4}$ precipitation (resulting in a decrease in $\mathrm{Ba}$ concentration of flowback fluids), cation exchange (resulting in a decrease in $\mathrm{Ca}$ and increase in $\mathrm{Na}$ ), and $\mathrm{NO}_{3}$ adsorption/desorption were also observed both in field and laboratory studies. Although oxidation of pyrite was significant in laboratory water-rock interaction experiments, field data show a mixing relationship between fracturing water and formation fluids with a $\mathrm{SO}_{4}$ concentration decrease and $\delta^{34} \mathrm{~S}$ increase during flowback. The detailed characterization of geochemical processes during hydraulic fracturing and flowback will help to understand the origin of solutes in flowback fluids. 